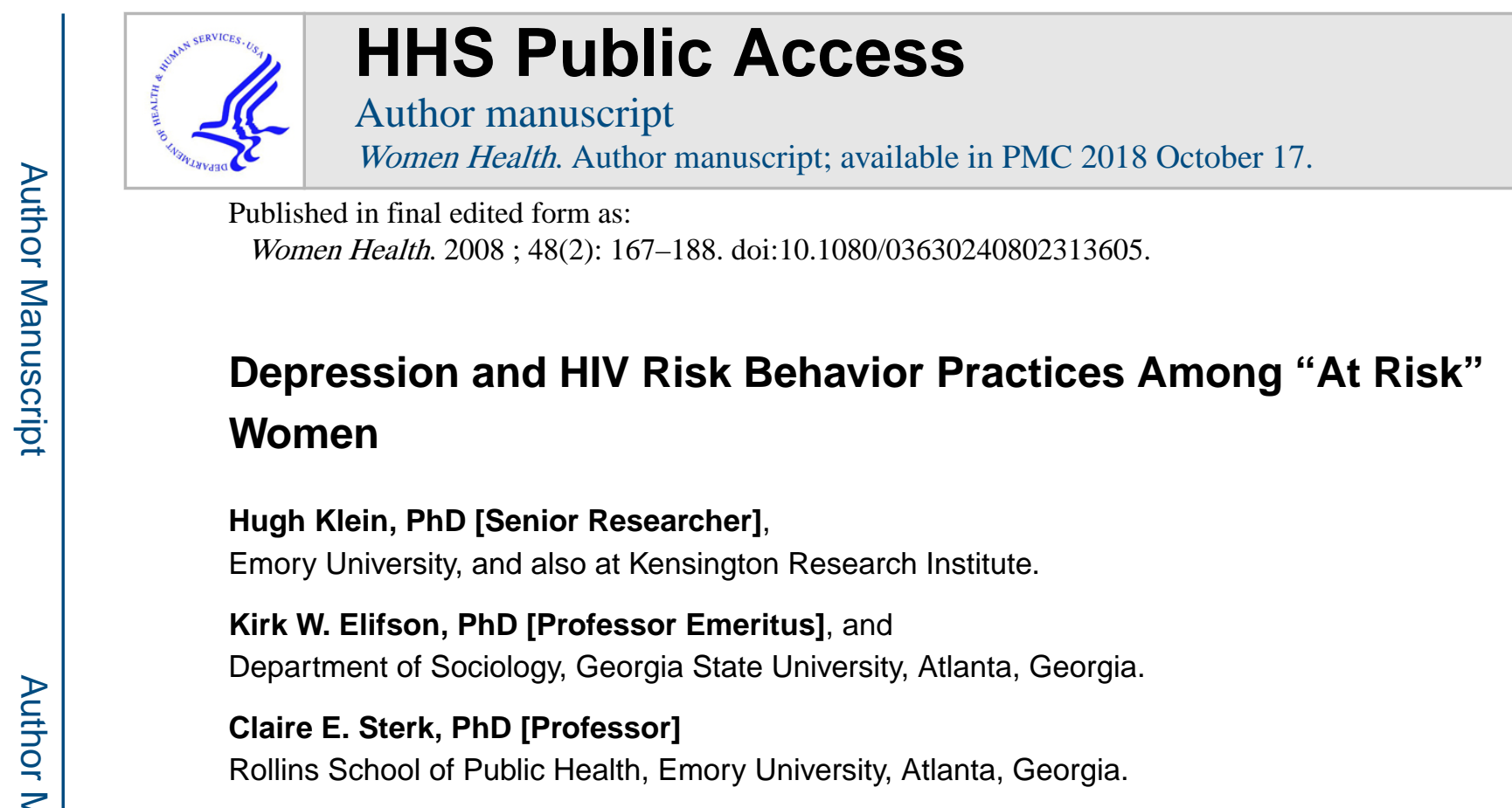

\begin{abstract}
In this study, we examined the relationship between depression and HIV-related risk behavior practices in a sample of 250 "at risk," predominantly African American women living in the Atlanta, Georgia metropolitan area. Interviews were conducted between August 1997 and August 2000. Street outreach efforts were used to identify potential study participants, with further expansion of the sample via targeted sampling and ethnographic mapping procedures.

Our conceptual model hypothesized a relationship between depression and HIV risk in which depression and condom-related attitudes were construed as intervening (or mediating) variables. A multivariate analysis was used to determine the relationship between depression and women's risk behaviors.

The results showed that depression was a key-mediating variable, having its primary influence on women's risky practices through its impact upon their attitudes toward using condoms. Factors associated with depression, included religiosity, closeness of family relationships, financial problems, childhood maltreatment experiences, and drug-related problems. The implications of these findings for prevention and intervention efforts are: (1) heightening faith community involvement and religious participation to decrease depression; (2) working with women whose familial bonds are in need of strengthening to combat depression; (3) providing mental health and counseling services to women who were emotionally and/or sexually abused during their formative years seems to help these women to recover from unresolved issues that may be fueling depression; (4) assisting "at risk" women who need training in money management issues to minimize their risk for depression; and (5) helping women drug abusers to receive treatment for their drug problems to combat their depression and lower their HIV risk.
\end{abstract}

\title{
Keywords
}

Women; depression; HIV risk behaviors; "at risk," predictors

Address correspondence to: Hugh Klein, Kensington Research Institute, 401 Schuyler Road, Silver Spring, MD 20910 (hughk@aol.com). 
Many researchers have shown that depression is greater among persons who are infected with HIV than among those who are not HIV-positive (Lichtenstein, Laska, \& Clair, 2002; Lyon \& Younger, 2001) and that depression levels are higher among HIV-infected persons whose viral loads and/or presenting symptoms are greater than their counterparts who have lower viral loads or fewer AIDS-related symptoms (Atkinson et al., 2007; Kalichman et al., 2002). Nearly all of the published depression-and-HIV literature has been based on studies of gay males or HIV-infected persons to determine the relationship between the extent of depressive symptoms and involvement in various types of HIV risk. Relatively little attention has been devoted to depression as a risk factor for engaging in HIV risk behaviors among other populations, particularly women. This is the focus of the present article.

Studies that examined the role that depression plays in women's HIV risk behaviors have been conducted with a variety of female populations, including community health clinic patients, drug treatment clients, community-based HIV intervention participants, and lowincome inner-city drug injectors, among others. In studies of African American women attending urban health centers (Orr et al., 1994) and female heroin addicts (Grella, Anglin, \& Annon, 1996), more depressive symptoms were associated with greater overall HIV risk. Another study of African American women who had a male intimate partner reported a direct relationship between the number of depressive symptoms and the likelihood of having been treated for a sexually transmitted infection (Laughon et al., 2007). Some researchers found a link between depression and women's drug-related HIV risk behaviors (Latkin \& Mandell, 1993; McCusker et al., 1995), and others reported an association between depression and the extent of women's sexual risk-taking practices (Morrill et al., 1996). Findings like these led Morrill and colleagues (2001) and Schilling et al. (1993) to conclude that HIV prevention and intervention efforts-particularly those targeting women-would be wise to address issues surrounding depression.

In the present study, we examined the relationship between depression and HIV risk behavior practices in a population of "at risk" women. We present a conceptual model for the manner in which we hypothesized depression to be related to their risk levels. We subjected this model to empirical testing and discuss the findings in light of their implications for HIV intervention efforts. We chose to focus on depression not only because of the general lack of research on this subject, but also because we anticipated that depression would be related to women's HIV risk practices. In great part, we believe, this is the result of the negative impact that depression has on feelings of hopefulness and how these feelings, in turn, shape the behaviors in which women engage. We hypothesized that women who were depressed would, by virtue of their depression, be more likely to feel hopeless about certain aspects of their lives and that this hopelessness, in turn, would make them less willing (and/or less able) to engage in the types of behaviors that keep them safe from HIV. Research on the relationship between depression and hopelessness among women supports this underlying supposition (Myers et al., 2002).

\section{THE CONCEPTUAL MODEL}

In this model (see Figure 1), depression is conceptualized as an intervening, or mediating, variable in the relationship predicting women's involvement in HIV risk behaviors. It is 
hypothesized to have a direct, negative effect on women's risky practices and to have an indirect effect, by adversely influencing their attitudes toward using condoms. Women experiencing greater levels of depression are expected to engage in more HIV-related risk behaviors and to have more negative attitudes toward using condoms. Regarding the former, our hypothesis is based on the supposition that greater levels of depression lead many people to experience greater indifference to their lives and to their well being (Cheng \& Chan, 2007; Van Der Does, 2002). This, we anticipate, will be manifested in an increased involvement in HIV risk practices. Some published studies have cited depression as a factor underlying an increased tendency to engage in unprotected sex (Adam et al., 2005). Regarding the latter, our hypothesis is that, for ostensibly the same reasons cited above, higher levels of depression will be linked with more-negative attitudes regarding condom use. There is support for this expectation in the scientific literature (De Vroome et al., 1998).

As the conceptual model in Figure 1 shows, depression is but one of several types of factors that might affect condom-related attitudes and HIV risk practices. Demographic characteristics, such as age, race, education, and others; background and experiences measures, such as relationship characteristics, knowing people with HIV or AIDS, relationship infidelity, and others; childhood maltreatment ex periences, such as sexual abuse, physical abuse, emotional abuse, and neglect; and substance use-related factors, such as amount of alcohol consumed, use of illegal drugs, the extent of women's drug-related problems, among others are all hypothesized to affect women's levels of depression, how they feel about using condoms, and their involvement in risky practices. Our hypothesis with regard to the influence of background and experiences measures (e.g., relationship quality) on depression is that women who report having more-supportive families and friends will demonstrate fewer depressive symptoms. This hypothesis has considerable support from the scientific literature (Compton, Thompson, \& Kaslow, 2005; Hall et al., 2004). Conversely, we hypothesize that women who were abused or neglected during their childhood and/or adolescent years will, as a group, demonstrate higher levels of depression than their peers who were not abused or neglected. This expectation, too, is derived from numerous published studies (Brown et al., 2007; Springer et al., 2007). Finally, we hypothesize a direct association between substance use/abuse influences and depressive symptomatology. Many studies have shown that substance abuse and drug-related problems are related to greater problems with depression (Falck, Wang, \& Carlson, 2008; Havens et al., 2006).

These hypothesized relationships stem from previous research, as well as the tenets of the theory of reasoned action/theory of planned behavior (Ajzen, 1992; Brown, 1999). Some elements from the health belief model (Brown, 1999; Fisher \& Fisher, 2000) are also evident in the model used to guide the present research (e.g., sociodemo-graphic factors preceding attitudinal measures, attitudes being among the key predictors of behavior, actual behavior as the principal outcome measure).

\section{METHODS}

\section{Overview and Sample}

The data for this study came from the Female Atlanta Study (Project FAST), which was conducted in the Atlanta, Georgia metropolitan area. One of the principal goals of this study 
was to examine life issues and challenges, substance use, psychological and psychosocial functioning, and a variety of HIV-related risk behaviors among adult "at risk" women. "At risk" was defined broadly and included, among others, the following seven characteristics: (1) living in areas known for high rates of drug abuse, (2) being either active users of illegal drugs and/or having an immediate family member who was a substance abuser, (3) being impoverished, (4) lacking adequate medical care and/or health insurance, (5) having a low education level, (6) being unemployed, and (7) having a criminal history.

\section{Eligibility}

To participate in the study, in addition to being considered an "at risk" woman, several other eligibility/inclusion criteria also had to be met. Each woman had to live in one of the study's catchment areas, be aged 18 years or older, and be able to conduct her interview in English. In addition, to ensure that a noninstitutionalized sample was obtained, women could not be enrolled in a substance abuse treatment program, incarcerated in a prison or jail, or be living in any other institutional setting at the time of their participation. The same inclusion/ eligibility criteria were used regardless of whether women were enrolled into the study on the basis of outreach workers' recruitment efforts or whether they were identified and enrolled based on referrals from previous study participants. In all, a review of the screening forms used in conjunction with Project FAST revealed that more than $82 \%$ of the women who were screened for participation in the study were, indeed, eligible. The participation was very high (slightly more than 95\%) among women who were screened and invited to take part in the study.

\section{Recruitment}

Outreach workers, familiar with the study's catchment areas and the target population, recruited the women into the study. In doing so, they relied on ethnographic strategies that are commonly applied in community-based studies (see below). For example, while engaging in the mapping of the physical and social environment of the area, they interacted with people and explained the purpose of their presence. Those who were interested in participating in the study were given a recruitment flyer. If a person was interested in participating right away, the outreach workers conducted initial screening interviews "on the street" to confirm potential participants' eligibility for the study. The initial recruitment was based largely on targeted sampling, including ethnographic mapping (Sterk, 1999; Watters \& Biernacki, 1989). The targeted neighborhoods were chosen because of their concentration of "at risk" women. These communities were "hot spots" of local drug activity characterized by frequent drug sales and widespread drug use. Within these community "hot spots," the outreach workers targeted places where "at risk" women were known to gather (e.g., laundromats, stores, playgrounds, churches, and activity centers), so as to maximize their recruitment efforts.

As the study progressed, a chain referral or "snowball" sampling technique was used to identify additional participants. After completion of the interview, each woman was asked to refer the research team to other women who might be interested in participating in the study. On average, interviews took two hours to complete. At the completion of the interview, each woman was paid $\$ 15$ for her participation and offered referrals to local health/social service 
agencies, as appropriate. Prior to undertaking interviews, the research protocols for this study were approved by the Institutional Review Boards at both Emory University and Georgia State University. Before they were interviewed for the study, all participants were required to provide signed, written consent to participate.

\section{Measures Used}

All of the data in Project FAST were based on self-reports. Women's level of depression was assessed with a scale measure comprised by 11 items taken from the Depression and

Anxiety Stress Scale 42 (DASS 42) developed by Lovibond and Lovibond (1995). This scale includes questions focusing on such depression-related elements as lacking interest in things, experiencing thoughts of suicide, having a poor appetite, and so forth. Items used to create this measure were scored on a five-point ordinal scale, with responses ranging from "not at all" to "a lot" to indicate the extent to which the characteristics in question distressed or bothered the study participants during the week prior to interview. This scale was found to be reliable (Cronbach alpha $=.86$ ). Previous studies have assessed the validity of the DASS 42 and have reported that it has excellent psychometric properties (e.g., convergent validity, discriminant validity, internal consistency, temporal stability) for the measurement of depression (Antony et al., 1998; Brown et al., 1997).

Condom-related attitudes were measured by adapting Brown's (1984) Attitudes Toward Condom Scale. Nine items, originally scored with a five-point Likert scale, were used to develop a single composite measure indicating women's overall attitudes toward using condoms. Individual items in the scale assessed condom-related feelings, such as permitting a partner to use a condom if he wants to, finding condoms embarrassing to use, thinking that condoms ruin the mood or the pleasurable aspects of sex, and so forth. The overall scale was found to have adequate reliability (Cronbach alpha $=.79$ ).

HIV risk behavior practices during the year prior to interview, the principal dependent measure used in these analyses, were assessed using summative scale measure (KuderRichardson-20 $=.61$ ). One point was added to the scale for each of the following items: (1) had sex while high or while partner was high on alcohol or other drugs, (2) had sex with an injection drug user, (3) had anal intercourse, (4) had sex with a man who might have had sex with other men, (5) traded sex for drugs, gifts, or money, (6) purchased sex with drugs, gifts, or money, (7) had multiple sex partners, and (8) had unprotected sex of any kind.

Demographic variables included age (coded as a continuous variable), race (coded as African American or other-than-African American), educational attainment (coded as less than high school graduate, high school graduate or equivalent, and at least some college education), and religiosity (coded as a continuous variable based on the interaction of frequency of religious service attendance and perceived importance of religion upon one's behaviors).

Background and experiences measures included the number of money-related problems experienced (a 10-item continuous scale measure) (Cronbach alpha $=.74)$, closeness of relationships with family members (a continuous measure based on responses to 12 items) $($ Cronbach alpha $=.88)$, closeness of relationships with friends (a continuous measure based 
on responses to eight items) (Cronbach alpha $=.96$ ), level of perceived support from one's family (a continuous measure based on responses to five items) (Cronbach alpha $=.88$ ), level of communication with dating and sexual partners (a continuous measure based on responses to seven items) (Cronbach alpha $=.81$ ), and past-year sexually transmitted infection testing history (coded yes/no). The family and social support measures were derived from items comprising the Inventory of Parent and Peer Attachment (Armsden \& Greenberg, 1987).

Childhood maltreatment variables examined included the amount of sexual abuse, physical abuse, emotional abuse, and neglect that women experienced during childhood or adolescence, and the total amount of maltreatment that they experienced (a continuous measure representing the sum of all of the preceding measures) (Cronbach alpha $=.90$ ). All of these constructs were assessed using items from Bernstein et al.'s (1994) Childhood Trauma Questionnaire, which utilizes a five-point ordinal scale (with response options ranging from "never" to "very often") for all component items.

Four substance use or exposure to substance abusers measures were also used in the analyses. These included measures examining (1) living with any person(s) using illegal drugs (coded yes/no), (2) the amount of alcohol used (a continuous measure constructed by multiplying the average number of drinks consumed per occasion by the number of days using alcohol during the preceding month), (3) the amount of illegal drugs used (a continuous measure constructed by summing the quantity-frequency amount of nine different drug types), and (4) the number of drug problems experienced (a continuous scale measure based on responses to 11 items indicating substance abuse and substance dependency, as specified in the DSM-IV (American Psychiatric Association, 1994) (KuderRichardson-20 $=.91$ ).

\section{Data Analysis}

Initially, the bivariate relationships between the independent variables and each of the endogenous or dependent variables (i.e., depression, condom-related attitudes, involvement in HIV risk behaviors) were examined. This entailed the use of Student's $t$ tests whenever the independent variable was dichotomous in nature (e.g., race, knowing anyone with HIV), analysis of variance whenever the independent variable was ordinal with fewer than five response levels (e.g., educational attainment), and simple regression whenever the independent variable was a continuous measure (e.g., amount of alcohol use, amount of childhood maltreatment). Variables that were found to be related significantly (i.e., $p<: 05$ ) or marginally (i.e., :10>p>:05) to the dependent measure in question were selected for initial entry into a multiple regression equation and then removed in stepwise fashion until a final "best fit" model could be derived, consisting only of statistically-significant variables. A model was deemed "best fit" when all statistically nonsignificant independent variables had been removed so that only significant items were retained. Both a backward elimination and a forward selection approach were used to examine each model, to make sure that the order of entering or removing items from the equations did not affect the outcomes. They did not. Consistent with the conceptual model being tested in this research, three such "best fit" models were developed — one for depression, one for condom-related attitudes, and one 
for involvement in HIV risk behaviors. Results are reported as statistically significant whenever $p<: 05$.

\section{RESULTS}

The proportions of study participants meeting each of the "at risk" criteria are displayed in Table 1. All of the women met at least one criterion, and most of them (67.2\%) met at least four of the criteria.

In all, 250 women participated in this study. Most $(88 \%)$ were racial minority group members, predominantly African American. The median age was 35 years (mean $=35.3$, s.d. $=13.2$, range $=18-72)$. About half $(53 \%)$ of the women were single, and one-quarter $(25 \%)$ were married or living as married at the time of their interview.

Seven items were associated significantly with women's levels of depression (see Figure 2), and were retained in the final multivariate model. The more religious women were, the less depression they experienced $(p<: 05)$ : Furthermore, women who had closer relationships with their family members were less depressed than their counterparts whose familial relationships were not as strong ( $p<: 05)$ : Coinciding with this, an independent effect was also observed for the amount of familial support women received during their childhood and adolescent years, with more supportiveness in their families-of-origin corresponding with lower levels of depression in adulthood $(p<: 05)$ : Consistent with this finding, experiencing sexual abuse $(p<: 01)$ or emotional abuse $(p<: 05)$ prior to adulthood were factors that heightened women's depression in adulthood. Our data also showed that the more moneyrelated problems $(p<: 05)$ and the more drug-related problems $(p<: 01)$ women had, the more depressed they tended to be. Combined, these seven factors accounted for $32.9 \%$ of the total variance in women's levels of depression.

Consistent with the hypothesized relationships presented in our original conceptual model, one demographic variable, one childhood maltreatment item, one substance use-related measure, and depression were found to be related to women's attitudes toward using condoms (see Figure 2). Younger women had more favorable attitudes toward the use of condoms than older women did $(p<: 001)$ : Women who had experienced childhood neglect reported more opposition to using condoms than their non-neglected counterparts $(p<: 001)$ : The more drug-related problems women had, the worse their attitudes toward condom use tended to be $(p<: 001)$ : Finally, the more depressed women were, the poorer their attitudes were regarding the use of condoms ( $p<: 05)$ : Taken together, these four variables, all of which were retained in the final multivariate equation, explained $22.6 \%$ of the total variance in women's condom-related attitudes.

Also generally consistent with our conceptual model, most of the hypothesized types of factors influencing women's HIV risk behavior involvement were observed (see Figure 2). The younger women were $(p<: 05)$ and the more religious they were $(p<: 001)$; the fewer the number of risky practices they reported. One of the background and experiences measures - having had a sexually transmitted disease during the preceding year-was associated with women's HIV risk behaviors. Women who had had an STD during the 
previous year engaged in nearly twice as many risky practices as their counterparts who had not contracted any STDs ( $p<: 001)$ : One childhood mal-treatment variable—childhood neglect - was also found to be related to HIV risk involvement, with neglected women reporting engaging in more HIV risk behaviors than their non-neglected peers $(p<: 05)$ : One of the drug-related measures-living with substance abusers-was associated with HIV risk practices $(p<: 01)$ : Women who lived with at least one abuser of alcohol and/or other drugs reported engaging in 50\% more HIV risk behaviors overall than women who did not live with any substance abusers. Finally, as hypothesized, the worse women's attitudes toward using condoms were, the greater the number of HIV risk behaviors they typically practiced ( $p<: 001$ ): Together, these six variables (all of which were retained in the final multivariate model) explained $27.9 \%$ of the total variance in women's HIV risk behavior practices, and slightly more than half of this explained variance (14.5\%) was explained by the two most consequential contributors to the model.

\section{DISCUSSION}

Overall, the conceptual model tested in this research received a great amount of support from the Project FAST data. As hypothesized, a variety of demographic characteristics, background and experiences measures, childhood maltreatment experiences, and drug userelated constructs were relevant to understanding women's levels of depression, their attitudes toward using condoms, and their involvement in HIV-related risk practices. As predicted, condom-related attitudes were related to HIV risk behaviors, and depression, in turn, was found to have a strong association with women's attitudes toward using condoms. Therefore, the model presented in Figure 1 seems to apply quite well and provides an empirically supported way of understanding the many factors that affect women's risky behavior practices, including the specific role that depression plays in those risky behaviors.

Specifically, that role is as a key-mediating variable, directly related to the variable found to have the single strongest association with women's risk practices - namely, their attitudes toward using condoms. Although depression had a strong direct relationship with HIV risk behaviors in the bivariate analyses conducted in conjunction with this research $(p<: 001-$ data not presented), this effect "washed out" in favor of the condom attitudes measure when the multivariate analysis was performed. Our data therefore revealed that the more depressed women were, the more opposition they tended to have toward using condoms; and the more opposed they were regarding condom use, the greater their involvement in HIV risks tended to be.

In light of the importance of depression in the overall equation regarding "at risk" women's HIV risk behavior practices, it is important to understand the factors that are related to their levels of depression. In the present research, we identified several such factors and wish to discuss them and their implications for ongoing and future HIV prevention and intervention efforts. First, we learned that religiosity was a protective factor against depression. Other scholars, too, have derived similar findings in their research (Keyes \& Reitzes, 2007; Woods et al., 1999). This finding is quite important because considerable evidence suggests that African Americans - who comprised most of the women taking part in Project FAST—are likely to utilize and trust services provided to them by their religious groups and spiritual 
advisors (Constantine et al., 2000; Smith, Simmons, \& Mayer, 2005). Therefore, HIV intervention programs working with minorities very well might improve their success rates if they strive to enhance religiosity and religious participation among their members.

Second, we found an inverse relationship between the closeness of women's relationships with their family members and their levels of depression. Women who felt closer emotionally to their relatives were less likely to be depressed than women who felt that they could not rely upon and/or receive support from their family members. In light of this finding, we believe that intervention programs aiming to improve women's levels of depression would be well advised to help them to strengthen their family ties. Specific ways that this might be done emerge when one considers the core elements of the family relationships measure used in this study. It consisted of components focusing on reliance upon family members, trusting one's family members, feeling supported versus criticized by one's family members, and receiving help from their relatives. Therefore, one way to strengthen women's relationships with their family members (in the hope of having a positive impact upon their levels of depression) might be to teach them ways to improve their communication skills. That way, any misunderstandings that arise between the women and their relatives can be resolved swiftly and effectively. For women for whom it is appropriate, making psychological counseling accessible might be another effective approach at helping them to identify and resolve issues pertaining to building and maintaining trust, autonomy, and independence and interdependence. Our find ings suggest that improving women's relationships with their family members will lead to reductions in their rates of depression, and that, in turn, may lead to subsequent benefits regarding their risk for HIV.

Similar to the preceding, the present research also showed depression levels were greater among women who had been abused sexually during childhood and/or adolescence, those who had been abused emotionally during their formative years, and among those who lacked basic support from their family members during these years. These findings are consistent with many other studies that have linked these types of maltreatment experiences with laterlife depression (Nelson et al., 2002; Springer et al., 2007). Regarding HIV intervention program efforts, the implications of these findings are fairly straightforward: Childhood maltreatment is a risk factor for the depression that underlies many "at risk" women's attitudes toward condom use and their involvement in risky behaviors; and childhood neglect specifically was found to have a direct effect upon women's attitudes toward using condoms and their HIV risk behavior practices. Women who once experienced abuse therefore constitute a risk group meriting targeted outreach and intervention efforts. Such women ought to be offered mental health referrals to appropriate agencies that are qualified to help them with any lingering, unresolved psychological issues that affect their lives. Other researchers, too, have addressed the link between childhood maltreatment experiences and HIV risk practices in adulthood, and they have discussed various intervention strategies that may help abused persons to reduce their risk for HIV (Champion et al., 2001; Greenberg, 2001).

In the present study, depression was also related to women's financial problems, with more money-related problems being related to greater levels of depression. This is not very 
surprising, considering how distressing it is to lack money for things like food, housing, and paying bills (all of which were elements of our financial problems measure). Other researchers have also noted a link between financial difficulties and depression among women (Kendler \& Gardner, 2001). With regard to the present research, this finding indicates a need to target poor women and help them improve their financial situation. This could be done in several ways. For women whose money problems stem from a lack of education, providing them with opportunities to complete their high school equivalency degree and/or to obtain some college-level or vocational-type training would be one promising approach. For women who have the requisite education but who lack marketable job skills, making career counseling, skills-building workshops, and vocational assistance available would be good ways to help them to improve their financial situation. Additionally, helping financially-constrained women to learn to manage their money as effectively as possible and showing them how to get out of debt and stay out of debt would also be worthwhile endeavors for community-based projects to undertake. Research on the effectiveness of such programs has been very encouraging, and some authors have noted the need for more educational opportunities and vocational rehabilitation services to be provided, particularly to disadvantaged women (Baletka, \& Shearer, 2001; Nunes-Dinis \& Barth, 1993). Given the association we found between money-related problems and depression, and given the proven success of programs designed to help low-income people to improve their economic circumstances, programs that can alleviate "at risk" women's financial woes are likely to derive positive benefits in the depression arena, too. That, in turn, our findings suggest, would decrease their likelihood of engaging in the risky practices that heighten their chances of acquiring HIV.

Finally, we found that, the more problems women experienced as a result of using illegal drugs, the more apt they were to experience depressive symptoms. In their study of predominantly African American men and women, Stein and Nyamathi (1999) also found a direct association between drug use and depression. Similarly, Kaslow and colleagues' (2002) research on factors differentiating low-income black women who had attempted suicide from those who did not found that drug problems were a risk factor for attempting suicide. It is also noteworthy, from the standpoint of the model developed and tested in conjunction with the present research, that drug problems were also linked to women having more negative condom-related attitudes. These findings point directly toward a need to discover ways to encourage drug-using women to stop using drugs. Not only would ending drug use help women to live healthier lives by virtue of no longer abusing drugs, but our findings also suggest that this might help them to reduce their levels of depression and improve how they feel about using condoms. Several researchers have investigated the role that drug treatment programs can play in ongoing efforts to curtail HIV risk practices, and they have obtained very encouraging results (Dushay et al., 2001; Longshore \& Hsieh, 1998). Our own research findings are consistent with the work done by these researchers and emphasize the importance of helping drug abusing "at risk" women to stop using drugs.

\section{Potential Limitations of the Present Research}

We would like to acknowledge three potential limitations of this research. First, Project FAST data were all based on uncorroborated self-reports. Therefore, the extent to which 
respondents underreported or overreported their involvement in risky behaviors is unknown. In all likelihood, the self-reported data can be trusted, as numerous authors have noted that persons in their research studies (which, like the present study, have included fairly large numbers of substance abusers) have provided accurate information about their behaviors (Anglin, Hser, \& Chou, 1993; Jackson et al., 2004).

A second possible limitation pertains to recall bias. Respondents were asked to report their beliefs, attitudes, and behaviors during the past 30 days, the past 90 days, and the past year, depending upon the measure in question. These time frames were chosen specifically: (1) to incorporate enough time in the risk behavior questions' time frames so as to facilitate meaningful variability from person to person, and (2) to minimize recall bias. Also of potential concern here would be differential rates of recall based on depression levels. For example, it is possible - perhaps even likely — that women suffering from greater levels of depression were less able to recall events with the same degree of clarity as their lessdepressed or not-depressed counterparts. The exact extent to which recall bias affected the data cannot be assessed, although other researchers who have collected data similar to that captured in Project FAST have reported that recall bias is sufficiently minimal that its impact upon study findings is likely to be small (Jaccard \& Wan, 1995). The complex nature of how depression may affect recall bias has been addressed by other researchers (Bellew \& Hill, 1990; Patten, 2003).

A third possible limitation of these data comes from the sampling strategy used. All interviews were conducted in the Atlanta, Georgia metropolitan area. Local or regional influences or subcultural differences between these women and those residing elsewhere could have affected the generalizability of the data. Additionally, the chain referral ("snowball") sampling approach used to identify study participants is not a random sampling strategy, and biases may be inherent in who was/not identified as potential study participants in Project FAST. A good discussion of the issues pertinent to this issue may be found in Heckathorn (1997), along with strategies that can be employed to minimize any bias that could result from the use of a chain-referral sampling approach.

\section{SUMMARY}

In summary, this study has shown that depression is related to "at risk" women's HIVrelated risk practices. Although bivariate analyses showed depression to be related strongly and directly to women's risky behaviors (more depression = more risk), the multivariate analyses we conducted revealed this relationship to be subordinate to that between condomrelated attitudes and risky behaviors. Noteworthy here, however, is that depression was one of the main multivariate factors related to women's condom-related attitudes, which was the strongest variable associated with their HIV risk behaviors. Therefore, it is best to conceptualize depression as an important mediating variable in the variety of factors that are related to "at risk" women's overall HIV-related risk practices. Because of its saliency as a mediating variable, understanding the factors underlying such women's levels of depression is crucial, since alleviating these antecedent influences is likely to lead ultimately to reduced behavioral risk. Accordingly, we examined the factors that heighten women's risk for experiencing depressive symptoms and discovered seven such factors. They were low levels 
of religiosity, less closeness with family members, less support from family members during the formative years, childhood sexual abuse, childhood emotional abuse, greater financial difficulties, and more problems stemming from illegal drug use.

\section{Acknowledgments}

The authors wish to acknowledge, with gratitude, the contributions made by Katherine Theall to the development of this manuscript.

This research was supported by a grant from the National Institute on Drug Abuse (R01-DA09819).

\section{REFERENCES}

Adam BD, Husbands W, Murray J, \& Maxwell J (2005). AIDS optimism, condom fatigue, or selfesteem? Explaining unsafe sex among gay and bisexual men. Journal of Sex Research, 42, 238-248. [PubMed: 19817037]

Ajzen I (1992). The theory of planned behavior. Organizational Behavior and Human Decision Processes, 50, 179-211.

American Psychiatric Association. (1994). Diagnostic and statistical manual of mental disorders (4th ed). Washington DC: American Psychiatric Association.

Anglin MD, Hser Y, \& Chou C (1993). Reliability and validity of retrospective behavioral self-report by narcotics addicts. Evaluation Review, 17, 91-103.

Antony MM, Bieling PJ, Cox BJ, Enns MW, \& Swinson RP (1998). Psychometric properties of the 42item and 21-item versions of the Depression Anxiety Stress Scales in clinical groups and a community sample. Psychological Assessment, 10, 176-181.

Armsden GC, \& Greenberg MT (1987). The Inventory of Parent and Peer Attachment: Individual differences and the relationship to psychological well-being in adolescence. Journal of Youth and Adolescence, 16, 427-454. [PubMed: 24277469]

Atkinson JH, Heaton RK, Patterson TL, Wolfson T, Deutsch R, Brown SJ, Summers J, Sciolla A, Gutierrez R, Ellis RJ, Abramson I, Hesselink RJ, McCutchan JA, \& Grant I (2007). Two-year prospective study of major depressive disorder in HIV-infected men. Journal of Affective Disorders, electronic publication date November 26.

Baletka DM, \& Shearer RA (2001). Counseling female offenders who abuse substances. TCA Journal, 29, 140-148.

Bellew M, \& Hill AB (1990). Negative recall bias as a predictor of susceptibility to induced depressed mood. Personality and Individual Differences, 11, 471-480.

Bernstein DP, Fink L, Handelsman L, Foote J, Lovejoy M, Wenzel K, Sapareto E, \& Ruggiero J (1994). Initial reliability and validity of a new retrospective measure of child abuse and neglect. American Journal of Psychiatry, 151, 1132-1136. [PubMed: 8037246]

Brown GW, Craig TKJ, Harris TO, Handley RV, \& Harvey AL (2007). Development of a retrospective interview measure of parental maltreatment using the Childhood Experience of Care and Abuse (CECA) instrument-A life course study of adult chronic depression-1. Journal of Affective Disorders, 103, 205-215. [PubMed: 17651811]

Brown IS (1984). Development of a scale to measure attitude toward the condom as a method of birth control. Journal of Sex Research, 20, 255-263.

Brown KM (1999). Theory of reasoned action/Theory of planned behavior. Retrieved on August 7 , 2008 from: http://hsc.usf.edu/ kmbrown/hlth_beh_models.htm

Brown TA, Chorpita BF, Korotitsch W, \& Barlow DH (1997). Psychometric properties of the Depression Anxiety Stress Scales (DASS) in clinical samples. Behaviour Research and Therapy, 35, 79-89. [PubMed: 9009048]

Champion JD, Shain RN, Piper J, \& Perdue ST (2001). Sexual abuse and sexual risk behaviors of minority women with sexually transmitted diseases. Western Journal of Nursing Research, 23, 241-254. [PubMed: 11291429] 
Cheng ST, \& Chan ACM (2007). Withdrawal, apathy and lack of vigor in late life depression: Factorial validity and relationship to diagnosis. Aging and Mental Health, 11, 532-537. [PubMed: 17882591]

Compton MT, Thompson NJ, \& Kaslow NJ (2005). Social environment factors associated with suicide attempt among low-income African Americans: The protective role of family relationships and social support. Social Psychiatry and Psychiatric Epidemiology, 40, 175-185. [PubMed: 15742221]

Constantine MG, Lewis EL, Conner LC, \& Sanchez D (2000). Addressing spiritual and religious issues in counseling African Americans: Implications for counselor training and practice. Counseling and Values, 45, 28-38.

De Vroome EMM, De Wit JBF, Stroebe W, Sandfort TGM, \& Van Griensven GJP (1998). Sexual behavior and depression among HIV-positive gay men. AIDS and Behavior, 2, 137-149.

Dushay RA, Singer M, Weeks MR, Rohena L, \& Gruber R (2001). Lowering HIV risk among ethnic minority drug users: Comparing culturally targeted intervention to a standard intervention. American Journal of Drug and Alcohol Abuse, 27, 501-524. [PubMed: 11506265]

Falck RS, Wang J, \& Carlson RG (2008). Depressive symptomatology in young adults with a history of MDMA use: A longitudinal analysis. Journal of Psychopharmacology, 22, 47-54. [PubMed: 18187532]

Fisher JD, \& Fisher WA (2000). Theoretical approaches to individual-level change in HIV risk behavior In Handbook of HIV prevention: AIDS prevention and mental health, eds. Peterson JL, \& DiClemente RJ, 3-55. New York: Kluwer Academic/Plenum Publishers.

Greenberg JB (2001). Childhood sexual abuse and sexually transmitted diseases in adults: A review of and implications for STD/HIV programmes. International Journal of STD and AIDS, 12, 777-783. [PubMed: 11779366]

Grella CE, Anglin MD, \& Annon JJ (1996). HIV risk behaviors among women in methadone maintenance treatment. Substance Use and Misuse, 31, 277-301. [PubMed: 8834263]

Hall LA, Peden AR, Rayens MK, \& Beebem LH (2004). Parental bonding: A key factor for mental health of college women. Issues in Mental Health Nursing, 25, 277-291. [PubMed: 14965847]

Havens JR, Sherman SG, Sapun M, \& Strathdee SA (2006). Prevalence and correlates of suicidal ideation among young injection versus noninjection drug users. Substance Use and Misuse, 41, 245-254. [PubMed: 16393745]

Heckathorn DD (1997). Respondent-driven sampling: A new approach to the study of hidden populations. Social Problems, 44, 174-199.

Jaccard J, \& Wan CK (1995). A paradigm for studying the accuracy of self-reports of risk behavior relevant to AIDS: Empirical perspectives on stability, recall bias, and transitory influences. Journal of Applied Social Psychology, 25, 1831-1858.

Jackson CT, Covell NH, Frisman LK, \& Essock SM (2004). Validity of self-reported drug use among people with co-occurring mental health and substance use disorders. Journal of Dual Diagnosis, 1, 49-63.

Kalichman SC, Difonzo K, Austin J, Luke W, \& Rompa D (2002). Prospective study of emotional reactions to changes in HIV viral load. AIDS Patient Care and STDs, 16, 113-120. [PubMed: 11945207]

Kaslow NJ, Thompson MP, Okun A, Price A, Young S, Bender M, Wyckoff S, Twomey H, Goldin J, \& Parker R (2002). Risk and protective factors for suicidal behavior in abused African American women. Journal of Consulting and Clinical Psychology, 70, 311-319. [PubMed: 11952189]

Kendler KS, \& Gardner CO (2001). Monozygotic twins discordant for major depression: A preliminary exploration of the role of environmental experiences in the aetiology and course of illness. Psychological Medicine, 31, 411-423. [PubMed: 11305849]

Keyes CL, \& Reitzes DC (2007). The role of religious identity in the mental health of older working and retired adults. Aging and Mental Health, 11, 434-443. [PubMed: 17612807]

Latkin CA, \& Mandell W (1993). Depression as an antecedent of frequency of intravenous drug use in an urban, nontreatment sample. International Journal of the Addictions, 28, 1601-1612. [PubMed: 8307668] 
Laughon K, Gielen AC, Campbell JC, Burke J, McDonnell K, \& O’Campo P (2007). The relationships among sexually transmitted infection, depression, and lifetime violence in a sample of predominantly African American women. Research on Nursing and Health, 30, 413-428.

Lichtenstein B, Laska MK, \& Clair JM (2002). Chronic sorrow in the HIV-positive patient: Issues of race, gender, and social support. AIDS Patient Care and STDs, 16, 27-38. [PubMed: 11839216]

Longshore D, Hsieh SC (1998). Drug abuse treatment and risky sex: Evidence for a cumulative treatment effect? American Journal of Drug and Alcohol Abuse, 24, 439-451. [PubMed: 9741945]

Lovibond SH, \& Lovibond PF (1995). Manual for the Depression Anxiety Stress Scales (2nd Ed). Sydney, Australia: Psychology Foundation.

Lyon DE, \& Younger JB (2001). Purpose in life and depressive symptoms in persons living with HIV disease. Journal of Nursing Scholarship, 33, 129-133. [PubMed: 11419307]

McCusker J, Goldstein R, Bigelow C, \& Zorn M (1995). Psychiatric status and HIV risk reduction among residential drug abuse treatment clients. Addiction, 90, 1377-1387. [PubMed: 8616466]

Morrill AC, Ickovics JR, Golubchikov VV, Beren SE, et al. (1996). Safer sex: Social and psychological predictors of behavioral maintenance and change among heterosexual women. Journal of Consulting and Clinical Psychology, 64, 819-828. [PubMed: 8803373]

Morrill AC, Kasten L, Urato M, \& Larson MJ (2001). Abuse, addiction, and depression as pathways to sexual risk in women and men with a history of substance abuse. Journal of Substance Abuse, 13, 169-184. [PubMed: 11547617]

Myers HF, Lesser I, Rodriguez N, Mira CB, Hwang WC, Camp C, Anderson D, Erickson L, Wohl M (2002). Ethnic differences in clinical presentation of depression in adult women. Cultural Diversity and Ethnic Minority Psychology, 8, 138-156. [PubMed: 11987591]

Nelson EC, Heath AC, Madden PAF, Cooper L, et al. (2002). Association between self-reported childhood sexual abuse and adverse psychosocial outcomes: Results from a twin study. Archives of General Psychiatry, 59, 139-145. [PubMed: 11825135]

Nunes-Dinis M, \& Barth RP (1993). Cocaine treatment and outcome. Social Work, 38, 611-617. [PubMed: 8211320]

Orr ST, Celentano DD, Santelli J, \& Burwell L (1994). Depressive symptoms and risk factors for HIV acquisition among Black women attending urban health centers in Baltimore. AIDS Education and Prevention, 6, 230-236. [PubMed: 8080707]

Patten SB (2003). Recall bias and major depression lifetime prevalence. Social Psychiatry and Psychiatric Epidemiology, 38, 290-296. [PubMed: 12799778]

Schilling RF, El-Bassel N, Gilbert L, \& Glassman M (1993). Predictors of changes in sexual behavior among women on methadone. American Journal of Drug and Alcohol Abuse, 19, 409-422. [PubMed: 8273763]

Smith J, Simmons E, \& Mayer KH (2005). HIV/AIDS and the black church: What are the barriers to prevention services? Journal of the National Medical Association, 97, 1682-1685. [PubMed: 16396060]

Springer KW, Sheridan J, Kuo D, Carnes M (2007). Long-term physical and mental health consequences of childhood physical abuse: Results from a large population-based sample of men and women. Child Abuse and Neglect, 31, 517-530. [PubMed: 17532465]

Stein JA, \& Nyamathi A (1999). Gender differences in relationships among stress, coping, and health risk behaviors in impoverished, minority populations. Personality and Individual Differences, 26, 141-157.

Sterk CE (1999). Building bridges: Community involvement in HIV and substance abuse research. Drugs and Society, 14, 101-121.

Van Der Does W (2002). Cognitive reactivity to sad mood: Structure and validity of a new measure. Behaviour Research and Therapy, 40, 105-120. [PubMed: 11762423]

Watters J, \& Biernacki P (1989). Targeted sampling: Options for the study of hidden populations. Social Problems, 36, 416-430.

Woods TE, Antoni MH, Ironson GH, Kling DW (1999). Religiosity is associated with affective status in symptomatic HIV-infected African-American women. Journal of Health Psychology, 4, 317326. [PubMed: 22021600] 


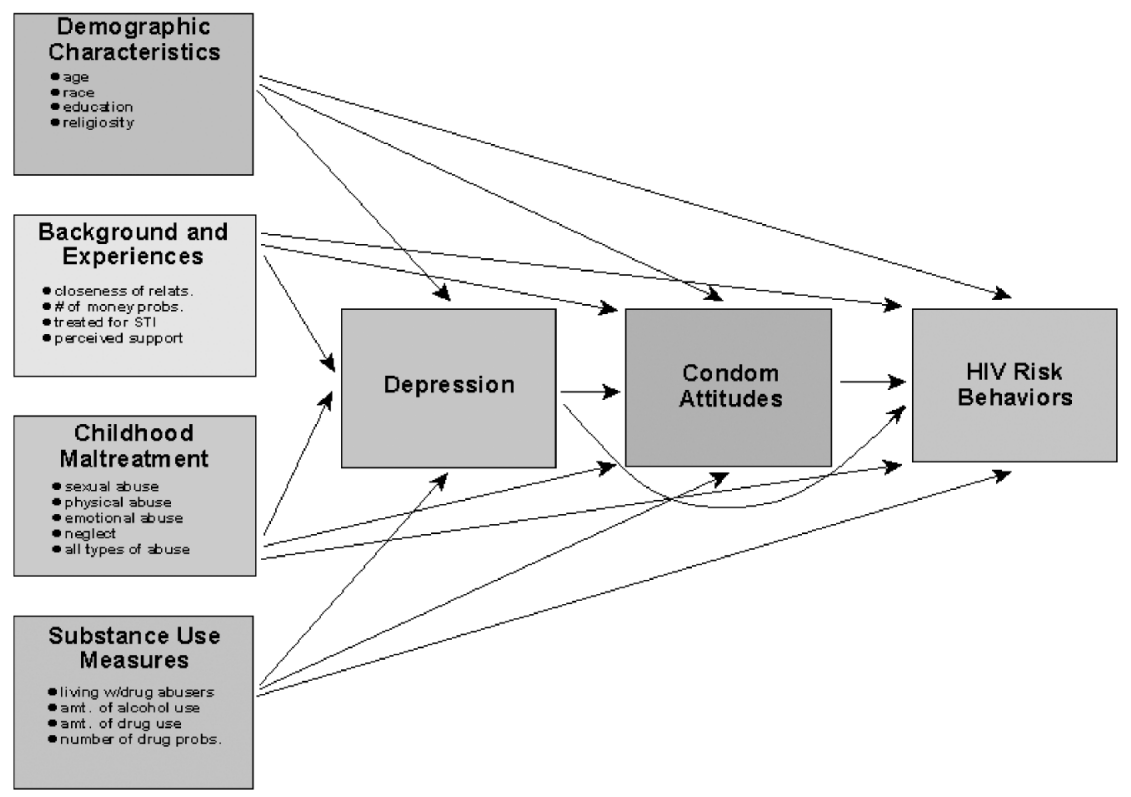

FIGURE 1.

Conceptual Model Being Tested 


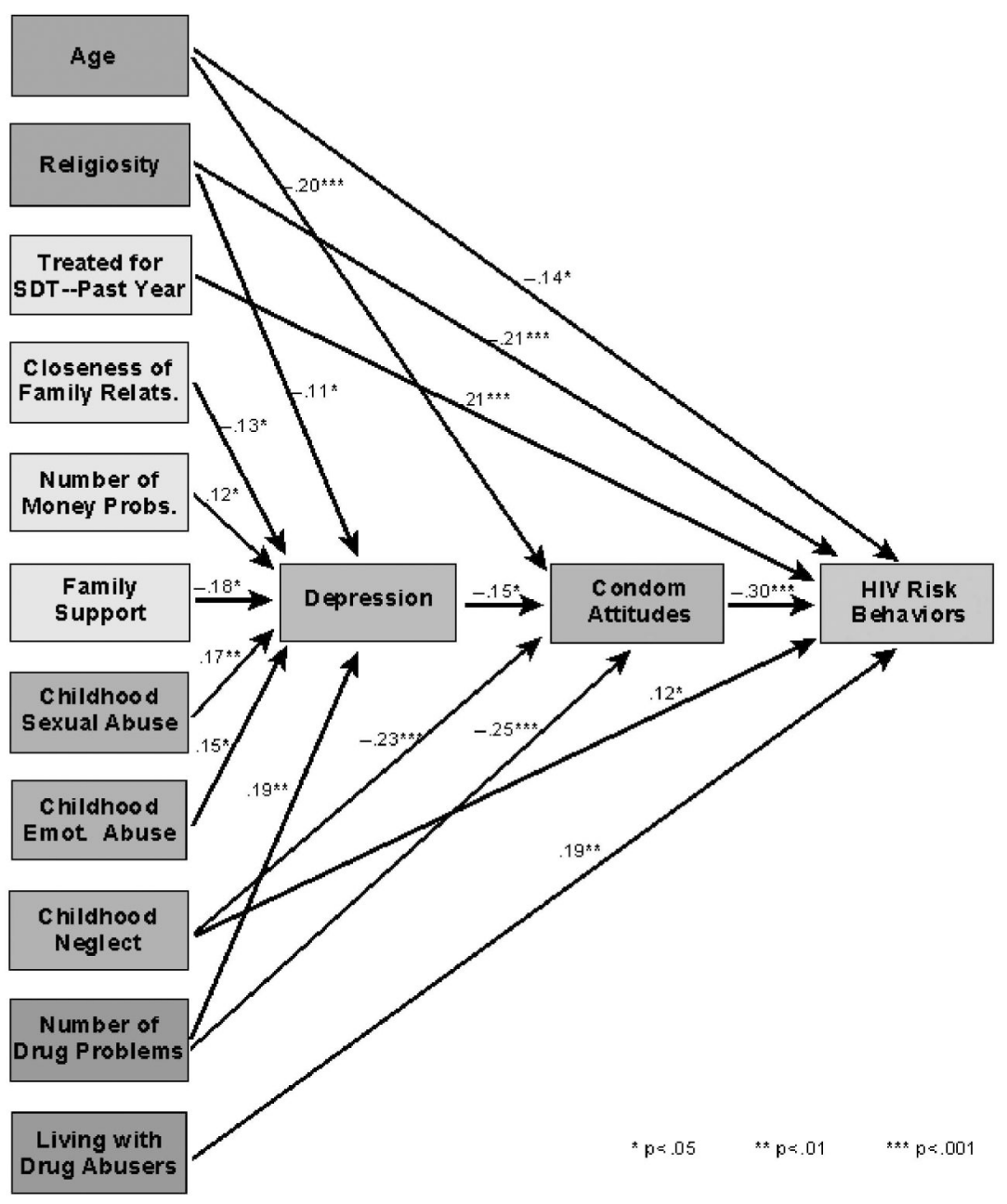

FIGURE 2.

Depression and HIV Risk Behaviors 
TABLE 1.

Description of the Sample

\begin{tabular}{lc}
\hline & \% of women \\
\hline Race & \\
African American & 86.4 \\
All others & 13.6 \\
Age (in years) & \\
18-29 & 38.0 \\
30-39 & 24.4 \\
40-49 & 24.0 \\
50 or older & 13.6 \\
Marital status & \\
Single & 52.6 \\
Married/living as married & 13.4 \\
Separated/divorced & 12.1 \\
All others & 21.9 \\
Educational attainment & \\
Less than high school & 40.4 \\
High school graduate & 34.8 \\
At least some college & 24.8 \\
"At risk"criteria & 42.4 \\
Living in drug-infested area & 24.8 \\
Drug user or close relative who abuses drugs & 67.4 \\
Income at/below poverty level & 40.4 \\
Less than high school education & 42.4 \\
Lacking needed medical care or having no medical insurance \\
Unemployed or disabled & 50.0 \\
Criminal history & 49.2 \\
Met 2-3 “at risk”criteria & 26.4 \\
Met 4-5 “at risk”criteria & \\
Met 6-7 “at risk"criteria & \\
\hline & \\
\hline
\end{tabular}

